\title{
Introducing Chromatographia Perspectives
}

\author{
André M. Striegel ${ }^{1}$ \\ Published online: 31 May 2021 \\ (c) This is a U.S. government work and not under copyright protection in the U.S.; foreign copyright protection may apply 2021
}

We are delighted to introduce, with this issue of CHROMATOGRAPHIA, a new series of articles, namely Perspectives. These are authored only on invitation by the Editors and are meant to be concise summaries, briefer than reviews, only a few pages long and perhaps as brief as one page. Perspectives dare an outlook on expected developments and major research directions in a field; they thus require corresponding seniority and expertise by the author(s), as they offer a more subjective, but visionary, outlook.

In the upcoming months, readers will see Perspectives on various techniques, each brought to you by one or more authorities in their respective fields. Our first group of articles will focus chiefly, though certainly not exclusively, on macromolecular separations. The reason for this is simply that macromolecular separation science happens to be my own area of expertise, that within which it was easiest for me to invite distinguished colleagues to contribute their expertise and vision. Also, I just happened to be the first of the journal Editors to have issued invitations! I've no doubt my fellow Editors will be inviting leaders in their own fields to contribute their knowledge and wisdom via this series, making for a more heterogeneous mix of topics across all areas of separation science. In these first articles, however, readers can learn where experts see the state-of-the-art residing, and where potentials and caveats lay, for techniques such as field-flow fractionation (FFF) in general and also several FFF subtechniques such as asymmetric flow FFF and thermal FFF, as well as for temperature gradient interaction chromatography, gradient polymer elution chromatography, hydrodynamic chromatography, two-dimensional liquid chromatography, and even that stalwart of polymer characterization that is size-exclusion chromatography. Beyond macromolecular separations, we shall also have a Perspective on two-dimensional liquid chromatography in general.

Our first Perspective article, which follows in this issue, is by Stepan Podzimek and Christoph Johann, both renowned experts in the field of asymmetric flow FFF. Here, they train their combined, insightful gaze at where the technique is today and where it could be in the near future, assuming certain practical limitations can be overcome. We thank them and the rest of the Perspectives authors who have already agreed to share with us their wisdom. Enjoy!

\section{Declarations}

Conflict of interest The author has no conflict of interest nor competing interests to declare.

Publisher's Note Springer Nature remains neutral with regard to jurisdictional claims in published maps and institutional affiliations.
André M. Striegel

andre.striegel@nist.gov

1 Chemical Sciences Division, National Institute of Standards and Technology (NIST), 100 Bureau Drive, MS 8390,

Gaithersburg, MD 20899-8390, USA 